\title{
Oncology Nurses' Perceptions of Obstacles and Supportive Behaviors at the End of Life
}

\author{
Renea L. Beckstrand \\ Brigham Young University - Provo, renea@byu.edu \\ Josie Moore \\ Brigham Young University - Provo \\ Lynn Callister \\ Brigham Young University - Provo
}

A. Elaine Bond

University of Jordan

Follow this and additional works at: https://scholarsarchive.byu.edu/facpub

Part of the Critical Care Nursing Commons, and the Other Nursing Commons

\section{Original Publication Citation}

Beckstrand, R. L., Moore, J., Callister, L. C., \& Bond, A. E. (2009). Oncology nurses' perceptions of obstacles and supportive behaviors in end-of-life care. Oncology Nursing Forum, 16(4), 446-453.

\section{BYU ScholarsArchive Citation}

Beckstrand, Renea L.; Moore, Josie; Callister, Lynn; and Bond, A. Elaine, "Oncology Nurses' Perceptions of Obstacles and Supportive Behaviors at the End of Life" (2009). Faculty Publications. 5309.

https://scholarsarchive.byu.edu/facpub/5309 
This material is protected by U.S. copyright law. Unauthorized reproduction is prohibited. To purchase quantity reprints, please e-mail reprints@ons.ora or to request permission to reproduce multiple copies, please e-mail pubpermissions@ons.ora.

\title{
Oncology Nurses' Perceptions of Obstacles and Supportive Behaviors at the End of Life
}

\author{
Renea L. Beckstrand, PhD, RN, CCRN, CNE, Josie Moore, RN, OCN ${ }^{\circledR}$, \\ Lynn Callister, RN, PhD, FAAN, and A. Elaine Bond, DNSc, RN
}

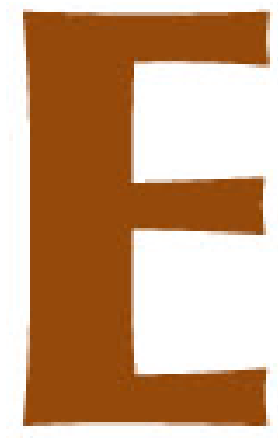

very year an estimated 1.4 million people are diagnosed with cancer and more than 560,000 die of the disease (Horner et al., 2009), making 1 out of every 4 deaths in the United States a cancer-related death (American Cancer Society [ACS], 2008). Cancer is the second most common cause of death in the United States, surpassed only by deaths from heart disease (ACS). With so many cancer-related deaths, oncology nurses are providing end-of-life (EOL) care for patients with cancer on a daily basis.

In 1995, the study to understand prognoses and preferences for outcomes and risks of treatments (SUPPORT) brought attention to shortcomings in EOL care of seriously ill hospitalized adults. Patients were reported to die in pain, with minimal communication with care providers and without having their identified wishes met (SUPPORT Investigators, 1995). In response, the World Health Organization (2002) issued a statement that patients with terminal illnesses and their caregivers deserve supportive and reliable care, which could improve patients' quality of life and help them to be as active as possible until the time of their death.

Two other national associations have spoken out regarding their visions for EOL care for patients with cancer. The Oncology Nursing Society (ONS) and the Association of Oncology Social Work (2003) position statement concluded that EOL care should reflect the needs of patients and families in a coordinated and interdisciplinary manner that is strengthened and supported by evidence-based research. The two national associations also stated that optimal EOL care should reduce the physical suffering patients with cancer experience through excellent assessment, reassessment, and management of physical symptoms and that psychosocial and spiritual care should be integrated to support coping.

Since the SUPPORT investigation, several studies have addressed various aspects of EOL care, such as patient and family perceptions of EOL care (Heyland et al., 2006; Lynn et al., 1997; Steinhauser et al., 2000), help for patients in discussing EOL issues with physicians (Clayton et al., 2007), and quality of medical care
Purpose/Objectives: To determine the magnitude of selected obstacles and supportive behaviors in providing end-of-life (EOL) care to patients with cancer as perceived by oncology nurses.

Design: Cross-sectional survey.

Setting: National survey sample.

Sample: A geographically dispersed national random sample of 1,000 Oncology Nursing Society members who had cared for inpatient patients with cancer, could read English, and had experience in EOL care.

Methods: Eligible respondents received a 68-item questionnaire in the mail adapted from previous studies and were asked to rate the size of obstacles and supportive behavior items in caring for patients with cancer at the EOL.

Main Research Variables: EOL, oncology, barriers, supportive behaviors, oncology nurses, and survey research.

Findings: Returns after three mailings yielded 375 usable questionnaires from 907 eligible respondents for a return rate of $41 \%$. The items with the highest perceived obstacle magnitude were (a) dealing with angry family members, (b) families not accepting what they are told about patients' poor prognosis, and (c) nurses being called away from dying patients to care for other patients. The three-highest scoring supportive behaviors were (a) allowing family members adequate time alone with patients after they died, (b) having social work or palliative care staff as part of the patient care team, and (c) having family members accept that patients are dying.

Conclusions: EOL care can be improved by working to decrease the highest-rated barriers and by continuing to support the highest-rated supportive behaviors.

Implications for Nursing: Oncology nurses are dedicated, experienced, and comfortable handling most issues in EOL care. Recommendations to support oncology nurses include strategies to interact effectively with angry, anxious, or overly optimistic family members as well as involving social work and palliative care staff on the oncology interdisciplinary team. In addition, the information regarding identified obstacles and supportive behaviors in oncology EOL care can be used to facilitate discussion and change within oncology interdisciplinary teams and improve EOL care for patients with cancer and their families.

at EOL (Yabroff, Mandelblatt, \& Ingham, 2004). Studies involving oncology nurses in the United States have been limited to nurses' perceptions of education related 
to EOL care (Coyne et al., 2007; White, Coyne, \& Patel, 2001). No study was found that identified barriers or supportive behaviors oncology nurses encounter in delivering EOL care.

\section{Research Questions}

Two research questions were addressed in the study: (a) What is the magnitude of selected obstacles to providing EOL care to patients with cancer as perceived by oncology nurses? (b) What are the supportive behaviors in providing EOL care to patients with cancer as perceived by oncology nurses?

By studying obstacles that stand in the way of providing optimal EOL care as well as supportive behaviors that increase the quality of EOL care, nursing educators and managers will be better able to educate and support bedside oncology nurses in delivering EOL care. In addition, nurses, nurse managers, and advanced practice nurses can use the information to work together with the interdisciplinary team to change and improve EOL care for patients with cancer and their families.

\section{Methods}

\section{Respondents}

Following institutional review board approval, a geographically dispersed random sample of 1,000 oncology nurses was obtained from ONS membership, which totals more than 36,000 RNs and other healthcare providers. ONS members who cared for inpatient patients with cancer, could understand English, and had experience in EOL care were considered eligible. Consent to participate was assumed upon return of the questionnaire.

\section{Instrument}

The Survey of Oncology Nurses' Perceptions of Endof-Life Care was adapted from two similar surveys with critical care nurses (Beckstrand \& Kirchhoff, 2005) and emergency nurses (Beckstrand, Smith, Heaston, \& Bond, 2008). The questionnaire was revised, where needed, to more closely apply to oncology EOL care. To strengthen content validity, information from literature and expert opinions were used to further revise initial obstacle and supportive behavior items. The questionnaire was piloted with 28 experienced oncology nurses from three different hospitals in one western state. Mean completion time for the questionnaire was 28 minutes for those who recorded time $(61 \%)$.

Recommendations from those 28 nurses were reviewed by an experienced oncology nurse. Three obstacles and four supportive behaviors were removed from the existing instrument because they did not directly relate to EOL care of patients with cancer. In ad- dition, the words "life support" and "life saving" in two existing items were changed to "aggressive care" and "aggressive treatments" to better reflect the oncology setting. Possible consequences of choosing aggressive treatments that were listed as examples were nausea, diarrhea, and fevers. The two new obstacle items added were physicians who insist on aggressive care until patients are actively dying and families being overly optimistic despite patients' poor prognosis.

The three supportive behaviors added based on pilot test results were (a) having social work or palliative care as part of the patient care team, (b) having social work or palliative care staff establish rapport with patients and families before patients are actively dying, and (c) having an experienced nurse model EOL care for a new nurse. Another supportive behavior, having educational inservice presentations (e.g., End-of-Life Nursing Education Consortium) on how to talk to and take care of dying patients, was added after reviewing the literature (Coyne et al., 2007; White et al., 2001). The final questionnaire contained 68 items, including 50 Likert-type items, four open-ended questions, and 14 demographic questions.

\section{Procedure}

Participant mailing information was purchased from ONS. Prior to mailing questionnaires, each participant was assigned a numerical code for ease of data management. The list matching names and code numbers was kept in a locked office. Questionnaires were mailed in October 2007 with a cover letter explaining the purposes of the study and a self-addressed stamped envelope. As an incentive for quick return, a one-dollar bill was included with each questionnaire in the first mailing. Two additional mailings, one in January $2008(\mathrm{~N}=754)$ and another in March $2008(\mathrm{~N}=610)$ to nonresponders were completed after the initial mailing of the questionnaire. Both mailings included a new cover letter, a copy of the questionnaire, and a self-addressed stamped envelope.

Oncology nurses were asked to rate the magnitude of listed obstacles and the supportive behaviors in giving EOL care to dying patients with cancer. Nurses also were asked to list any additional obstacles and supportive behaviors they had encountered while caring for dying patients that had not been included as items on the questionnaire.

When questionnaires were returned, responses were entered into SPSS ${ }^{\oplus}$ version 10.0. Frequencies and measures of central tendency and dispersion were calculated. Items were ranked from highest to lowest on the basis of mean scores to determine which items were the largest obstacles and the most supportive behaviors. Cronbach alpha scores were calculated to determine internal consistency estimates of reliability. Responses 
from open-ended questions were analyzed with content analysis and categorized with like items placed in the same category and frequency counts made.

\section{Results}

Of 1,000 potential respondents, 93 were eliminated from the study because the questionnaire could not be delivered $(n=4)$, the nurse was retired $(n=4)$, or recipients reported they were ineligible $(n=85)$. Usable responses were received from 375 nurses for a response rate of $41 \%$.

Of the respondents who reported their gender $(\mathrm{n}=$ 369), 351 were women (94\%) (see Table 1). Respondents ranged in age from $23-72$ years $(\bar{X}=48$ years). They were employed as staff or charge nurses $(71 \%)$, clinical nurse specialists $(7 \%)$, or other $(23 \%)$, primarily as managers and educators. Reported practice settings included nonprofit community hospitals ( $58 \%$ ), for-profit community hospitals (11\%), university medical centers $(20 \%)$, county hospitals $(4 \%)$, federal hospitals $(2 \%)$, state hospitals $(1 \%)$, county hospitals $(4 \%)$, military hospitals (1\%), and other (3\%).

Respondents worked a mean of 36.1 hours per week, had been RNs for a mean of 18 years, and had worked in oncology for a mean of 12.5 years. Certification as an oncology certified nurse $\left(\mathrm{OCN}^{\circledast}\right)$ or advanced oncology certified nurse $\left(\mathrm{ACON}^{\circledR}\right)$, certified ostomy care nurse, or advanced drawing charge nurse had been achieved by $242(67 \%)$ of the respondents, of which $207(54 \%)$ were currently certified. The mean number of years as an $\mathrm{OCN}^{\oplus}$ was 7.4. The mean number of years as an advanced certified nurse was 7.7. Most nurses (69\%) reported caring for more than 30 dying patients (highest listed option on the instrument) throughout their careers.

The highest level of education in the sample of oncology nurses was diploma (8\%), associate degree (22\%), bachelor's degree (49\%), master's degree (20\%), doctoral degree (1\%), and other (less than $1 \%$ ).

\section{Obstacles}

On a scale of 0 (not an obstacle) to 5 (extremely large obstacle), mean obstacle scores ranged from a 1.02-3.56 for the 25 items (see Table 2). Cronbach alpha for the 26 obstacle size items was high at 0.92 .

Eight of the top 10 obstacles related directly to family attitudes and behaviors. The highest-rated obstacle to providing EOL care was nurses having to deal with angry family members $(\bar{X}=3.56)$, followed closely by families not accepting the patient's poor prognosis $(\overline{\mathrm{X}}=$ 3.55). Two similar top 10 obstacles were the fourth-ranked item, dealing with anxious family members $(\overline{\mathrm{X}}=3.51)$, and the sixth-ranked item, the family being overly optimistic about patients' poor prognosis $(\bar{X}=3.44)$. In addi-
Table 1. Demographic Characteristics

\begin{tabular}{lrrc}
\hline Characteristic & $\overline{\mathrm{X}}$ & SD & Range \\
\hline Age (years) & 48 & 10.8 & $23-72$ \\
Years as RN & 18 & 11.1 & $1.5-45$ \\
Years in oncology & 12.5 & 8.3 & $1-40$ \\
Hours worked per week $_{\text {Number of beds in oncology unit }}$ & 36.1 & 10.5 & $0-80$ \\
Years as OCN $^{\circledR 3}$ & 7.4 & 11.6 & $0-100$ \\
Years as AOCN $^{\circledR}$ & 7.7 & 3.6 & $1-25$ \\
\hline Characteristic & \multicolumn{2}{c}{$\mathbf{n}$} & $\%$ \\
\hline
\end{tabular}

\section{Gender}

Female

Male

Did not report

Dying patients cared for

More than 30

21-30

11-20

5-10

Less than 5

Highest degree

Diploma

Associate

Bachelor

Master

Doctoral

Ever certified as $\mathrm{OCN}^{\circledast}$ or advanced certified nurse

Yes

No

351

18

6

94

5

2

248

26

48

26

13

Currently $\mathrm{OCN}^{\varpi}$ or advanced

certified nurse

Yes

No

Ever participated in ELNEC

program

Yes

No

\section{Practice area}

Staff or charge nurse

Clinical nurse specialist

Other (manager, educator)

Hospital type

Community, nonprofit

Community, profit

University medical center

Federal

State

County

Military

Other

$\begin{array}{rr}69 & 20 \\ 268 & 80 \\ 262 & 71 \\ 25 & 7 \\ 84 & 23 \\ & \\ 211 & 58 \\ 40 & 11 \\ 72 & 20 \\ 7 & 2 \\ 4 & 1 \\ 16 & 4 \\ 2 & 1 \\ 12 & 3\end{array}$

$N=375$

$\mathrm{AOCN}^{\circledR}$ - advanced oncology certified nurse; ELNEC - End-ofLife Nursing Education Consortium; $\mathrm{OCN}^{\otimes}$ - oncology certified nurse

Note. Because of missing data and rounding, not all $\mathrm{n}$ values total the sample size and not all percentages total 100 .

tion, families not wanting patients to be overly sedated by too many doses of pain medication $(\bar{X}=3.36)$ ranked seventh, frequent phone calls from various family members for updates on patient condition $(\overline{\mathrm{X}}=3.35)$ ranked eighth, 
Table 2. Mean Obstacle Size Reported by Oncology Nurses With Regard to End-of-Life Care

\begin{tabular}{|c|c|c|c|c|}
\hline Rank & Obstacle & $\bar{x}$ & SD & $\mathbf{n}$ \\
\hline 1. & Angry family members & 3.56 & 1.07 & 372 \\
\hline 2. & Families not accepting what the physician tells them about patients' poor prognosis & 3.55 & 0.98 & 370 \\
\hline 3. & $\begin{array}{l}\text { Being called away from patients and families to help with a new admit or to help other nurses } \\
\text { care for their patients }\end{array}$ & 3.53 & 1.07 & 365 \\
\hline 4. & Anxious family members & 3.51 & 1.03 & 371 \\
\hline 5. & Physicians who insist on aggressive care until patients are actively dying & 3.47 & 1.39 & 371 \\
\hline 6. & Families being overly optimistic despite patients' poor prognosis & 3.44 & 1.09 & 368 \\
\hline 7. & $\begin{array}{l}\text { Patients' families not wanting patients to be overly sedated because of too many pain medica- } \\
\text { tion doses }\end{array}$ & 3.36 & 1.2 & 370 \\
\hline 8. & $\begin{array}{l}\text { Families and friends who continually call the nurse wanting an update on patients' condition } \\
\text { rather than calling the designated family member for information }\end{array}$ & 3.35 & 1.25 & 367 \\
\hline 9. & Intrafamily fighting about whether to continue or stop aggressive treatment & 3.31 & 1.14 & 371 \\
\hline 9. & Patients having pain that is difficult to control or alleviate & 3.31 & 1.3 & 371 \\
\hline 11. & $\begin{array}{l}\text { Family members not understanding the consequences of continuing aggressive treatments (e.g., } \\
\text { chemotherapy-induced nausea, diarrhea, and anemia) }\end{array}$ & 3.3 & 1.1 & 369 \\
\hline 12. & $\begin{array}{l}\text { Employing life-sustaining measures at families' requests even though patients signed advanced } \\
\text { directives requesting no such treatment }\end{array}$ & 3.18 & 1.64 & 370 \\
\hline 13. & Physicians who are overly optimistic to patients and families about patients surviving & 3.09 & 1.22 & 372 \\
\hline 14. & $\begin{array}{l}\text { Not enough time to provide quality end-of-life care because nurses are consumed with activities } \\
\text { that are trying to save patients' lives }\end{array}$ & 3.08 & 1.22 & 371 \\
\hline 15. & $\begin{array}{l}\text { Continuing treatments for dying patients even though the treatments cause patients pain or } \\
\text { discomfort }\end{array}$ & 3.01 & 1.5 & 367 \\
\hline 16. & Lack of education and training regarding end-of-life care and family grieving & 2.85 & 1.5 & 368 \\
\hline 17. & Poor design of units that do not allow for privacy of dying patients or grieving family members & 2.7 & 1.78 & 370 \\
\hline 18. & Patients having too many visitors & 2.62 & 1.38 & 366 \\
\hline 19. & Not really knowing what to say to grieving patients or their families & 2.56 & 1.47 & 370 \\
\hline 20. & Dealing with cultural differences families employ in grieving for dying family members & 2.53 & 1.2 & 370 \\
\hline 21. & Families, for whatever reason, are not with patients when they die. & 2.46 & 1.22 & 368 \\
\hline 22. & Nurses knowing about patients' poor prognosis before families are told the prognosis & 2.4 & 1.4 & 368 \\
\hline 23. & Pressure to limit family grieving after patients die to accommodate a new admit to that room & 2.14 & 1.75 & 364 \\
\hline 24. & No available support person for families such as a social worker or religious leader & 2.03 & 1.48 & 371 \\
\hline 25. & Restrictive visiting hours & 1.02 & 1.6 & 372 \\
\hline
\end{tabular}

and intrafamilial fighting about whether to continue or stop aggressive treatment $(\overline{\mathrm{X}}=3.31)$ ranked ninth.

Oncology nurses identified the third-ranked obstacle as being called away from dying patients and families to care for other patients $(\overline{\mathrm{X}}=3.53)$. This highly-ranked obstacle also was supported by free text data where 10 of 78 nurses reported staffing ratios, high nurse and patient load, or lack of time to care for dying patients as large obstacles in delivering EOL care.
The fifth-ranked obstacle involved physicians who insisted on aggressive care until patients are actively dying $(\bar{X}=3.47)$. Patients having pain that is difficult to control or alleviate ranked ninth. The two obstacles also were mentioned in the free text data. Nurses commented that physicians were reluctant to refer patients to hospice or palliative care $(n=10)$ and were either uncomfortable or inexperienced in ordering adequate pain medication $(n=9)$. 
Three items perceived by oncology nurses to be the smallest obstacles included restrictive visiting hours $(\overline{\mathrm{X}}=$ 1.02); no available support person for the family, such as a social worker or religious leader $(\bar{X}=2.03)$; and pressure to limit family grieving after patients' deaths to accommodate a new admit to that room $(\bar{X}=2.14)$.

\section{Supportive Behavior Items}

On a scale of 0 (not a help) to 5 (extremely large help), mean scores for the 24 supportive behavior items ranged from a high of 4.58 to a low of 3.72 (see Table 3). Cronbach alpha for the 24 supportive behaviors was high at 0.9 . Two of the top 10 supportive behaviors identified by oncology nurses were things nurses could control such as allowing family members adequate time alone with patients after death $(\bar{X}=4.58)$ and providing a peaceful bedside scene after patients die $(\bar{X}=4.5)$.

The second most helpful factor was having a social work or palliative care staff as part of the team $(\bar{X}=$ 4.55). In addition, other helpful interdisciplinary factors were having the physicians involved agree about the direction of patients' care $(\overline{\mathrm{X}}=4.51)$ and having social work or palliative care staff develop a rapport with patients and families before patients are actively dying $(\bar{X}=4.38)$.

Within nursing, having experienced nurses model EOL care for new nurses $(\bar{X}=4.39)$ had the sixthhighest mean score, and verbal support from a fellow nurse after patients die $(\overline{\mathrm{X}}=4.38)$ scored as the seventh-highest.

Oncology nurses identified having family members accept that patients are dying $(\overline{\mathrm{X}}=4.53)$ as the third-most supportive behavior. The last 2 top 10 helpful behaviors involved families, including teaching family members how to act around dying patients $(\bar{X}=4.33)$, and having one family member as a designated contact for other family members regarding patient information $(\bar{X}=4.33)$.

Lowest scoring supportive behaviors were having families physically help care for dying patients $(\bar{X}=$ 3.72 ), nurses drawing on their own previous experiences with EOL care of patients or family members $(\bar{X}=3.78)$, and having fellow nurses cover other patients to allow nurses to get away from the unit for a few minutes after patients die $(\overline{\mathrm{X}}=3.78)$.

\section{Discussion}

Participants were highly experienced and knowledgeable, with more than half of the nurses reporting having been certified as an $\mathrm{OCN}^{\circledR}$ at some time. Nurses in this sample were members of their professional nursing organization and may possibly be more experienced, on average, than oncology nurses who are not members of ONS. Nurses in the study may realize the importance and power nursing organizations can have on nursing practice, so their responses to obstacle and supportive behavior questionnaire items may be different than responses from a sample of nurses who do not belong to ONS. Because the sample was randomly selected, geographically dispersed, and of adequate size, results are generalizable to the population of ONS members who work in an inpatient oncology setting.

\section{Obstacle Size}

The high mean score of reported obstacles by oncology nurses is notably lower than the critical care nurses highest mean obstacle score $(\bar{X}=4.03$ ) (Beckstrand \& Kirchhoff, 2005) and the emergency nurses highest mean obstacle score $(\bar{X}=3.8)$ (Heaston, Beckstrand, Bond, \& Palmer, 2006). The lower mean obstacle score may reflect the fundamental nature of oncology nursing as it relates to EOL issues. Cancer is second only to heart disease in cause of adult deaths in the United States (ACS, 2008). Oncology nurses frequently are exposed to EOL situations and, through experience, become experts in working with families during EOL. Deffner and Bell (2005) noted that older, more experienced nurses felt more comfortable discussing death and EOL issues with patients and families.

Families are an integral part of EOL care in oncology and provide a unique set of challenges. Eight of the top 10 obstacles to EOL care identified in the study directly related to families. Oncology nurses identified dealing with angry, anxious, and overly optimistic families as well as families who do not understand or accept patients' prognosis as significant obstacles to EOL care of patients with cancer. Dealing with upset family members is further complicated by individual family members' reaction to information. Some family members desire open communication about disease staging, treatment options, and prognosis, whereas others would rather not know (Royak-Shaler et al., 2006). Waldrop (2007) noted that the most common psychological and emotional responses to grief were predominantly intense sadness and anger. Oncology nurses must not only work with individual families to understand dying patients' situations, they must do so as families are in a heightened state of anxiety, depression, nervousness, restlessness, and fear, leading to difficulty remembering, concentrating, and completing tasks (Waldrop).

The three smallest obstacles (a) visiting hours that are too restrictive, (b) no available support person for the family such as a social worker or religious leader, and (c) pressure to limit family grieving to accommodate a new admit to that room reflect the importance of clear, family-oriented hospital policies and administrative support in EOL care. Open visiting hours, adequate numbers of social workers on staff, and willingness to allow ample family grieving time reflect a few areas of overall hospital support in EOL care. 


\begin{tabular}{|c|c|c|c|c|}
\hline Rank & Supportive Behavior & $\bar{x}$ & SD & $\mathbf{n}$ \\
\hline 1. & Allowing family members adequate time to be alone with patients after death & 4.58 & 0.61 & 366 \\
\hline 2. & Having social work or palliative care staff as part of the patient care team & 4.55 & 0.68 & 365 \\
\hline 3. & Having family members accept that patients are dying & 4.53 & 0.65 & 369 \\
\hline 4. & Having the physicians involved agree about the direction of patients' care & 4.51 & 0.69 & 368 \\
\hline 5. & Providing a peaceful bedside scene after patients die & 4.5 & 0.71 & 367 \\
\hline 6. & Having experienced nurses model end-of-life care for new nurses & 4.39 & 0.79 & 368 \\
\hline 7. & $\begin{array}{l}\text { Having social work or palliative care staff establish rapport with patients and families before } \\
\text { patients are actively dying }\end{array}$ & 4.38 & 0.75 & 367 \\
\hline 7. & $\begin{array}{l}\text { Having fellow nurses tell you, "You gave great care to that patient," or some other words of } \\
\text { support after patients die }\end{array}$ & 4.38 & 0.79 & 367 \\
\hline 9. & $\begin{array}{l}\text { Teaching families how to act around dying patients such as saying to them, "She can still hear, } \\
\text { it is okay to talk to her." }\end{array}$ & 4.33 & 0.76 & 366 \\
\hline 9. & $\begin{array}{l}\text { Having one family member be the designated contact person for all other family members re- } \\
\text { garding patient information }\end{array}$ & 4.33 & 0.8 & 369 \\
\hline 11. & Having enough time to educate families about their loved ones' expected process of dying & 4.26 & 0.77 & 370 \\
\hline 11. & $\begin{array}{l}\text { A unit designed so that families have a place to go to grieve in private away from patients' } \\
\text { rooms }\end{array}$ & 4.26 & 0.85 & 370 \\
\hline 13. & Having a unit schedule that allows for continuity of care for dying patients by the same nurses & 4.25 & 0.84 & 369 \\
\hline 14. & $\begin{array}{l}\text { Having family members thank you or in some other way show appreciation for your care of } \\
\text { patients who die }\end{array}$ & 4.21 & 0.9 & 367 \\
\hline 14. & $\begin{array}{l}\text { Allowing families unlimited access to dying patients even if it at times conflicts with nursing } \\
\text { care }\end{array}$ & 4.21 & 1.06 & 364 \\
\hline 16. & Talking with patients about their feelings and thoughts about dying & 4.19 & 0.82 & 366 \\
\hline 17. & Having educational inservice classes on how to talk to and take care of dying patients & 4.09 & 0.94 & 366 \\
\hline 18. & $\begin{array}{l}\text { Having fellow nurses put their arms around you, hug you, pat you on the back, or give some } \\
\text { other kind of brief physical support after patients die }\end{array}$ & 4.01 & 1.1 & 367 \\
\hline 19. & $\begin{array}{l}\text { After patients die, having support staff members compile all the necessary paperwork for you } \\
\text { that must be signed by families before they leave the unit }\end{array}$ & 3.94 & 1.13 & 360 \\
\hline 20. & Having the physician meet in person with the families after patients die to offer support & 3.85 & 1.13 & 366 \\
\hline 21. & Having a support person outside of the work setting who will listen to you after patients die & 3.83 & 1.22 & 366 \\
\hline 22. & $\begin{array}{l}\text { Nurses drawing on their own previous experience in end-of-life care with either patients or } \\
\text { family members }\end{array}$ & 3.78 & 1.04 & 366 \\
\hline 22. & $\begin{array}{l}\text { Having fellow nurses take care of other patients while you get away from the unit for a few mo- } \\
\text { ments after patients die }\end{array}$ & 3.78 & 1.07 & 365 \\
\hline 24. & Having families physically care for dying patients & 3.72 & 1.04 & 367 \\
\hline
\end{tabular}

\section{Supportive Behavior Size}

Mean scores for supportive behaviors were much higher than for obstacles because the highest scoring behaviors usually were behaviors that were under nurses' control and, therefore, were perceived as very helpful. Two of the top 10 supportive behaviors, allowing fam- ily members time after patients' deaths and providing a peaceful bedside scene after death, were not only not under control of nurses but occurred after patients had died. Because oncology EOL care intensely involves families, nurses' roles in EOL care do not end with patients' last breath. Albinsson and Strang (2003) identified supporting the family after patients die as a significant 
part of oncology EOL care. Oncology nurses face EOL care and issues on a regular basis, so they focus on and maximize family support through things over which they have control. In addition, the nurses identified the helpfulness of interdisciplinary support from social workers and palliative care staff. Because nurses often are called away from dying patients (third-largest obstacle size), the expertise of social work and palliative care staff provide essential support for nurses, patients, and families. Often, physicians do not discuss with patients and families the incurableness of the illness or short life expectancy until the last month or even week of patients' lives (Cherlin et al., 2005). Even when patients and families are aware of the gravity of the situation, family members may require additional time to understand and accept the information (Cherlin et al.). Social work and palliative care team members provide essential support to nurses, patients, and families throughout patients' illnesses.

The least supportive behavior was having family help to physically care for patients. This may have been rated as the lowest supportive behavior because of the efficiency of this highly experienced sample of nurses or because of families' hesitancy in participating in the physical care of dying loved ones.

Although the importance of educational inservice classes to help student and new nurses competently and compassionately care for dying patients has been repeatedly emphasized (Caton \& Klemm, 2006; Mallory, 2003), nurses in the study gave the helpfulness of educational inservice classes a surprisingly low ranking (17th). At the same time, those nurses ranked having experienced nurses mentor new nurses as the sixth-highest supportive behavior. The focus on personal mentoring rather than impersonal group instruction from educational in-service classes most likely reflects the wishes of experienced nurses who participated in the study.

The common top 10 obstacle items among oncology, critical care, and emergency nurses related to issues surrounding dying patients' families (Beckstrand \& Kirchoff, 2005; Beckstrand et al., 2008; Heaston et al., 2006). These common highly-rated obstacles included nurses having to deal with angry family members and family members who will not accept patients' poor prognosis, do not understand the consequences of aggressive treatment, and continually call the nurse for information on patients' conditions. Interestingly, the four obstacles were consistently high across multiple settings and identify universal issues in EOL care.

Five of the top 10 supportive behaviors reported by oncology nurses also were reported by emergency and critical care nurses. They were (a) allowing family members time after patients die, (b) providing a peaceful bedside scene after death, (c) having family members accept that patients are dying, (d) having physicians agree about the direction of patient care, and (e) having one family member as the designated contact for information. These five supportive behaviors were common across all three areas of nursing.

\section{Limitations}

As discussed previously, nurses in the study were highly experienced in nursing and in oncology. Although their experience makes them experts in their field and valuable respondents, their perceptions of EOL care may differ from their potentially less-experienced colleagues. In addition, the frequency of occurrence of the obstacles and supportive behaviors was not analyzed to determine the overall magnitude of each obstacle and supportive behavior. Highly rated obstacles and supportive behaviors should not be interpreted as those that also occur most frequently in oncology EOL care.

\section{Conclusions}

The purpose of the study was to determine the biggest obstacles and most supportive behaviors surrounding EOL care as perceived by oncology nurses. Although respondents reflect only a small percentage of ONS members, important information was obtained from this random sample of experienced nurses.

Oncology nurses are dedicated, experienced, and comfortable handling most issues in EOL care. This is especially true of obstacles and supportive behaviors that are in nurses' control. Recommendations to support nurses who deliver EOL care to patients with cancer include strategies to effectively interact with angry, anxious, or overly optimistic family members, and to work with family members to understand and accept the prognosis and dying process of their loved ones. Further recommendations include involving social work and palliative care staff on the oncology interdisciplinary team to support physicians, nurses, patients, and families in EOL care. Lastly, nurses, nurse managers, and advanced practice nurses can use this information regarding identified obstacles and supportive behaviors to facilitate discussion and change within their interdisciplinary teams, and ultimately to improve EOL care for patients with cancer and their families.

Renea L. Beckstrand, PhD, RN, CCRN, CNE, is an associate professor and research coordinator, Josie Moore, $\mathrm{RN}, \mathrm{OCN}^{\text {* }}$, is a nurse practitioner student, and Lynn Callister, RN, PhD, FAAN, is a professor, all in the College of Nursing at Brigham Young University in Provo, UT; and A. Elaine Bond, DNSc, RN, is a director of the nursing graduate program in the College of Nursing at the University of Jordan in Amman. No financial relationships to disclose. Beckstrand can be reached at renea@byu .edu, with copy to editor at ONFEditor@ons.org. (Submitted June 2008. Accepted for publication September 19, 2008.)

Digital Object Identifier: 10.1188/09.ONF.446-453 


\section{References}

Albinsson, L., \& Strang, P. (2003). Differences in supporting families of dementia patients and cancer patients: A palliative perspective. Palliative Medicine, 17(4), 359-367.

American Cancer Society. (2008). Cancer facts and figures, 2008. Retrieved April 7, 2008, from http://www.cancer.org/downloads/ STT/2008CAFFfinalsecured.pdf

Beckstrand, R.L., \& Kirchhoff, K.T. (2005). Providing end-of-life care to patients: Critical care nurses' perceived obstacles and supportive behaviors. American Journal of Critical Care, 14(5), 395-403.

Beckstrand, R.L., Smith, M.D., Heaston, S., \& Bond, A.E. (2008), Emergency nurses' perceptions of size, frequency, and magnitude of obstacles and supportive behaviors in end-of-life care. Journal of Emergency Nursing, 34(3), 290-300.

Caton, A.P., \& Klemm, P. (2006). Introduction of novice oncology nurses to end-of-life care. Clinical Journal of Oncology Nursing, 10(5), 604-608.

Cherlin, E., Fried, T., Prigerson, H.G., Schulman-Green, D., JohnsonHurzeler, R., \& Bradley, E.H. (2005). Communication between physicians and family caregivers about care at the end of life: When do discussions occur and what is said? Journal of Palliative Medicine, 8(6), 1176-1185.

Clayton, J.M., Butow, P.N., Tattersall, M.H., Devine, R.J., Simpson, J.M., Aggarwal, G., et al. (2007). Randomized controlled trial of a prompt list to help advanced cancer patients and their caregivers to ask questions about prognosis and end-of-life care. Journal of Clinical Oncology, 25(6), 715-723.

Coyne, P., Paice, J.A., Ferrell, B.R., Malloy, P., Virani, R., \& Fennimore, L.A. (2007). Oncology End-of-Life Nursing Education Consortium training program: Improving palliative care in cancer. Oncology Nursing Forum, 34(4), 801-807.

Deffner, J.M., \& Bell, S.K. (2005). Nurses' death anxiety, comfort level during communication with patients and families regarding death, and exposure to communication education. Journal for Nurses in Staff Development, 21(1), 19-23.

Heaston, S., Beckstrand, R.L., Bond, A.E., \& Palmer, S.P. (2006). Emergency nurses' perceptions of obstacles and supportive behaviors in end-of-life care. Journal of Emergency Nursing, 32(6), 477-485.

Heyland, D.K., Dodek, P., Rocker, G., Groll, D., Gafni, A., Pinchora, D., et al. (2006). What matters most in end-of-life care: Perceptions of seriously ill patients and their family members. Canadian Medical Association Journal, 174(5), 627-633.

Horner, M.J., Ries, L.A.G., Krapcho, M., Neyman, N., Aminou, R., Howlader, N., et al. (Eds). (2009). SEER cancer statistics review, 1975-2006. Retrieved June 6, 2009 from http://seer.cancer.gov/ csr/1975_2006/index.html

Lynn, J., Teno, J.M., Phillips, R.S., Wu, A.W., Desbiens, N., Harrold, J., et al. (1997). Perceptions by family members of the dying experience of older and seriously ill patients. SUPPORT Investigators. Study to Understand Prognoses and References for Outcomes and Risks of Treatments. Annals of Internal Medicine, 126(2), 97-106.

Mallory, J.L. (2003). The impact of a palliative care educational component on attitudes toward care of the dying in undergraduate nursing students. Journal of Professional Nursing, 19(5), 305-312.

Oncology Nursing Society and Association of Oncology Social Work. (2003). End-of-life care [Position statement]. Retrieved May 16, 2007, from http://www.ons.org/publications/positions/endof lifecare.shtml

Royak-Schaler, R., Gadalla, S.M., Lemakau, J., Ross, D., Alexander, C., \& Scott, D. (2006). Family perspectives on communication with healthcare providers during end-of-life cancer care. Oncology Nursing Forum, 33(4), 753-760.
Steinhauser, K.E., Clipp, E.C., McNeilly, M., Christakis, N.A., McIntyre, L.M., \& Tulsky, J.A. (2000). In search of a good death: Observations of patients, families, and providers. Annals of Internal Medicine, 132(10), 825-832.

SUPPORT Investigators. (1995). A controlled trial to improve care for seriously ill hospitalized patients. The Study to Understand Prognosis and Preferences for Outcomes and Risks of Treatments. JAMA, 274(20), 1591-1598.

Waldrop, D.P. (2007). Caregiver grief in terminal illness and bereavement: A mixed-methods study. Health and Social Work, 32(3), 197-206.

White, K.R., Coyne, P.J., \& Patel, U.B. (2001). Are nurses adequately prepared for end-of-life care? Journal of Nursing Scholarship, 33(2), 147-151.

World Health Organization. (2002). National cancer control programme: Policies and managerial guidelines (2nd ed.). Geneva, Switzerland: Author.

Yabroff, K.R., Mandelblatt, J.S., \& Ingham, J. (2004). The quality of medical care at the end-of-life in the USA: Existing barriers and examples of process and outcome measures. Palliative Medicine, 18(3), 202-216. 